\title{
Research of Dynamic Recrystallization of Ferrite in a Low Carbon Steel
}

\author{
WANG Meng, LIU Yangbo, SUN Qingsong, TONG Qian
}

Shou Gang Resaerch Institute of Technology

Keywords: low carbon steel, ferrite, cementite particle, dynamic recrystallization, particle-stimulated nucleation

Abstract. The microstructure evolution of ferrite in a low carbon steel during hot uniaxial compression tests at 700C and 0.01s-1 was investigated by means of OM, SEM, EBSD and TEM. In order to investigate the effect of cementite particles size on dynamic recrystallization (DRX) of ferrite, two kinds of different microstructures consisting of ferrite with similar size and cementite particles with different sizes were adopted by quenching and tempering of a low carbon steel. The results showed that large cementite particles acted as nucleation sites for dynamic recrystallization (DRX) of ferrite by particle-stimulated nucleation (PSN) mechanism, due to the formation of large orientation gradient near them during hot deformation. In the earlier stage, DRX nuclei were mainly formed near cementite particles with size larger than $1 \mu \mathrm{m}$. With increasing strain, the nuclei would also be formed near particles with size between 0.5 to $1 \mu \mathrm{m}$. On the contrary, because of much smaller orientation gradient and pinning effect on the dislocation and sub-boundary, the cementite particles with size smaller than 0.3

$\square \mathrm{m}$ retarded dynamic recovery an

Hot-work tool steels are widely used at various heat-treatment (i.e. tempering conditions) states to obtain the mechanical properties requested by the industrial application, like hot forging, casting, hot-rolling, extrusion, where the steel endures cyclic thermal and mechanical loads [1]. Most of the investigations indicate that cyclic plasticity is responsible, in parallel to wear and abrasion, of tool limit lifetime [2,3].

As reported in our previous paper, DRX of ferrite would take place and be promoted when microstructures of specimens consist of ferrite plus fine cementite particles[4]. Further investigations are needed to explore effect of cementite particle size on the DRX of ferrite.

Recrystallization is favored from particle-deformed zones due to large orientation gradient near the zone. Recrystallization of this type is referred as particle stimulated nucleation (PSN)[5]. It was first discovered by Humphreys[6,7]when he investigated annealing of cold rolling Cu-Zn alloys. Large second phase particles $(>0.6 \mu \mathrm{m})$ will promote static recrystallization nucleation. Thereafter, PSN also was observed during hot deformation. For instance, McQueen et al. reported that second phase particles larger than 0.6 $\mu \mathrm{m}$ will promote the DRX of Al-Mg alloy during hot torsion test[8]. However, particles will retard the DRX with decreasing the size of particles. During studying the annealing deformed microstructure, Nes[9]also discovered that there is a critical particle size for PSN, and the particle will retard the DRX when particle size is less than the critical size $\left(0.3^{\mu \mathrm{m}}\right)$.

\section{Experimental procedure}

Material used in this study is Q235 low grade mild steel, whose chemical composition (wt\%) was listed as following: C 0.171, S 0.013, P 0.017, Si 0.09, Ni 0.03, Cu 0.01, Al 0.025, Mo 0.01. Ingot was forged to rods with $15 \mathrm{~mm}$ in diameter within the temperature range of 850-1100 C, austenized at 980 $\mathrm{C}$ for $13 \mathrm{~min}$, then water quenched, after that tempered at $710 \mathrm{C}$ for 6 hours (noted as specimen 1) and 60 hours (noted as specimen 2). As shown in Fig. 1, their ferrite grain sizes are equivalent and approximately $15 \mu \mathrm{m}$. However, sizes and distribution of cementite of two specimens are quiet different; the sizes and distance of specimen 2 are larger than those of specimen 1 . As-treated specimens were machined into cylinder with $8 \mathrm{~mm}$ in diameter and $15 \mathrm{~mm}$ in length. The hot compression test was carried on a Gleeble 1500 at $700 \mathrm{C}$ with a strain rate of $0.01 \mathrm{~s}-1$. 


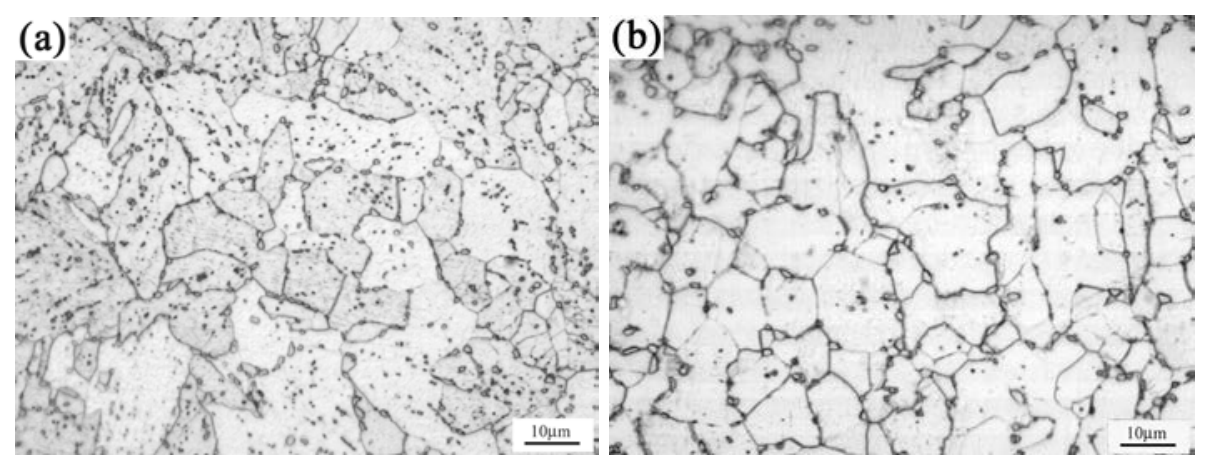

Fig.1 Microstructures of the low carbon steel quenched at 980C/15min, tempered at $710 \mathrm{C} / 6 \mathrm{~h}(\mathrm{a})$ and quenched at $980 \mathrm{C} / 15 \mathrm{~min}$, tempered at $710 \mathrm{C} / 60 \mathrm{~h}(\mathrm{~b})$

\section{Result and discussion}

\section{Microstructure evolution}

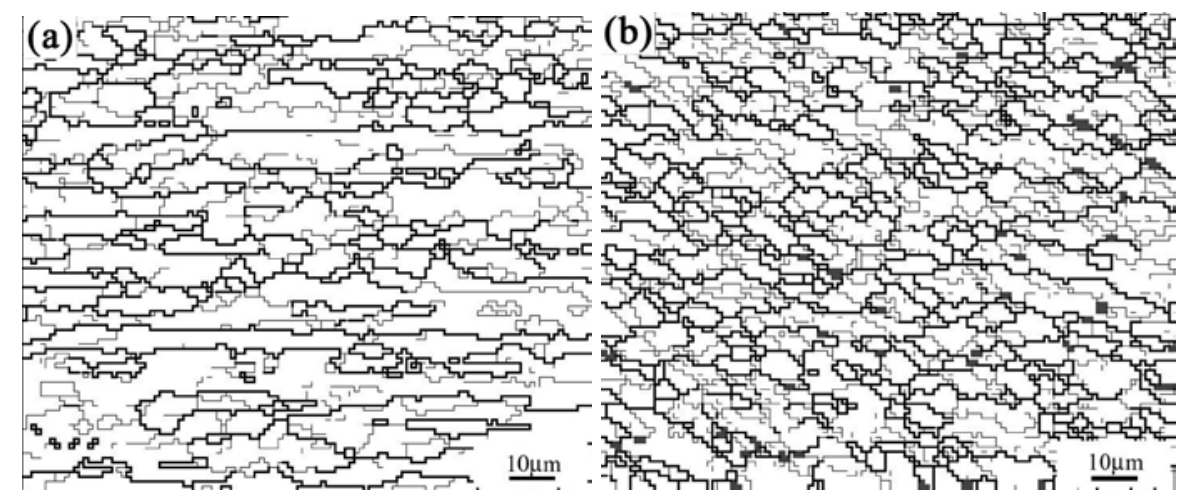

Fig.2 EBSD misorientation maps of the sample No.1 (a) and No.2 (b) at strain of 1.6, LAGB and

Deformed microstructures of the two samples deformed at 700C, 0.01s-1 to the strain of 1.60 are shown in Fig. 2. Grain boundaries and EBSD misorientation maps of two samples appeared. As shown in Fig. 2, the amount of the DRX grain of ferrite (equiaxed grain enclosed by HAGB) of specimen 1 is less than that of specimen 2. That is to say, the DRX level of ferrite of specimen 2 is higher than that of specimen 1 . For specimen 1 , there are a great mount of small cementites inside the servicer deformed grain, while the contrary is truth for specimen 2 . What is more, a large number of HAGBs and LAGBs were observed in specimen 2, while it is on the contrary in specimen 1.
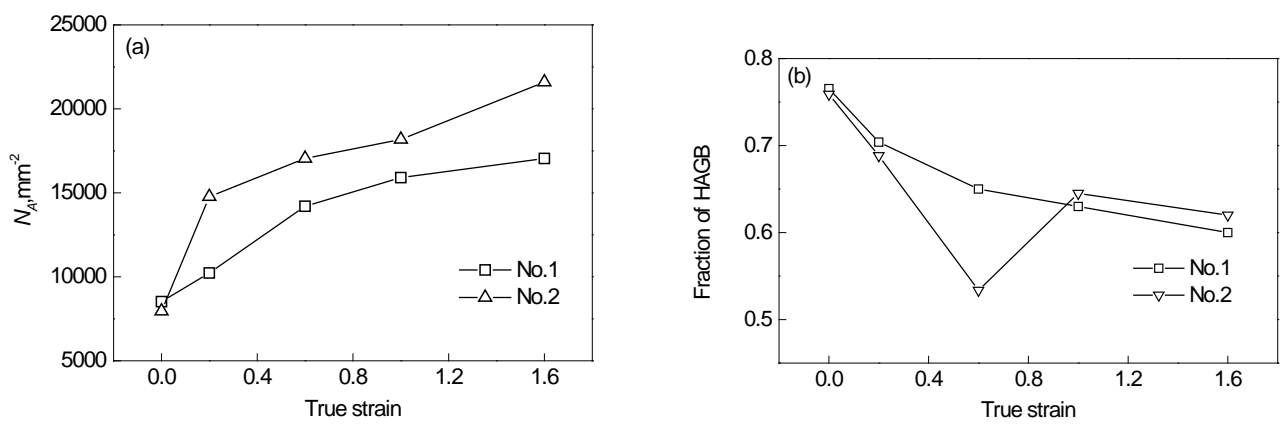

Fig.3 Variations of grain number density (a) and fraction of HAGB with strain in the two samples obtained by EBSD maps.

Fig.3a shows the variation of grain number density with strain in the two specimens, which presents directly process of DRX of ferrite during deformation. The velocity and degree of DRX of 
specimen No.2 were higher than these of specimen No.1. The variation of HAGB fraction with strain in the two specimens was shown in Fig. 3b. For specimen No.1, the fraction of HAGB decreases rapidly with increasing strain till 0.6 , then decreases gradually. For specimen No.2, the fraction of HAGB decreases rapidly, drops down to trough at 0.6 , then increases till 1 , after that remains the same.

The number of HAGBs will increase because of DRX of ferrite during deformation for both specimens. However, dynamic recovery of ferrite is prone to take place during hot deformation and a great number of LAGBs will form inside the deformed ferrites in the early stage. Therefore, increase of the fraction of LAGBs lead to decrease the fraction of HAGB. The velocity of DRX of specimen No.2 is high and the number of DRX grain is large. However, the dynamic recovery of ferrite leads to a distinct decrease of the fraction of HAGB in the early stage of deformation. In another words, comparing to specimen No.2, the reason of smaller decline rate of the fraction of HAGB is uncompleted dynamic recovery of ferrite. With strain increasing, the DRX of ferrite continues and the number of HAGBs increases clearly. That is the reason that the fraction of HAGB increases obviously. Up to a certain strain, the fraction of HAGB increases gradually because the balance between DRX and dynamic recovery. For specimen No.1, the velocity of DRX is low, and up to a larger strain, the balance between DRX and dynamic recovery is reached and the fraction of HAGB decreases slowly.

\section{Effects of cementite particles on the DRX of ferrite}

1) PSN mechanism of large cementite particles $(>0.5 \mu \mathrm{m})$

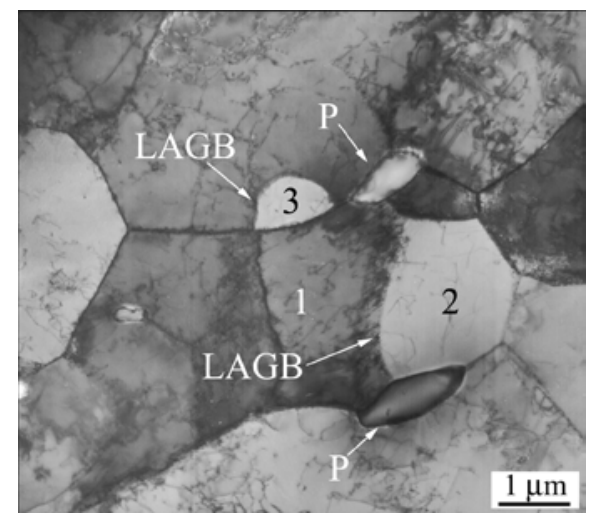

Fig.4TEM image of PSN near cementite particles with size larger than $1.0 \mu \mathrm{m}$.

The driving force of the growth of nuclei was provided by the storage energy (higher dislocation density close to particles) of the deformation zone. As shown in Fig. 4, PSN nucleus(grain marked by 2) grows up to grain (marked by 1 ) which contained lots of dislocations by the migration of LAGB between the grain1 and PSN nucleus(grain marked by 2). LAGBs increase their angle by absorbing dislocations during migration.

At the early stage of deformation, PSN nuclei mainly form in the vicinity of large cementites ( $>1$ $\mu \mathrm{m})$. At last, PSN nuclei can form around medium-size particles $(0.5-1.0 \mu \mathrm{m})$ because of particles co-nucleation and strain accumulation[10], which increases the degree of the DRX of ferrite and further refines the microstructures .

2) Effect of small dispersed cementite particles $(<0.3 \mu \mathrm{m})$ on the DRX of ferrite

The dynamic recovery and DRX are actually a process of release of stored energy during hot deformation by the way of dislocation annihilation, dislocation rearrangement and HAGB migration. For specimen No.1, small cementite particles cannot cause a large distorted area. Therefore they pin dislocations (shown in Fig. 5a) and inhibit dynamic recovery. In addition, small particles pin LAGBs, decrease the mobility of LAGBs, inhibit the transformation from LAGBs to HAGBs and retard DRX.

Small particles inhibit the dynamic recovery by pinning dislocations. Therefore the number of grain increased and the fraction of HAGBs decreased of specimen No.1 are smaller than those of specimen No.2. At last, the small $(<0.3 \mu \mathrm{m})$ dispersed particles cannot induce strain gradient large enough and dislocation density high enough to form PSN nuclei[8,9], and inhibit the dynamic 
recovery and DRX by pinning dislocations and grain boundaries in the mean time. Therefore the total number of grain boundary of specimen No.1 in the deformed area is much less than that of specimen No.2 as shown in Fig. 5. The ferrite grains remain severely deformed and are not refined further.
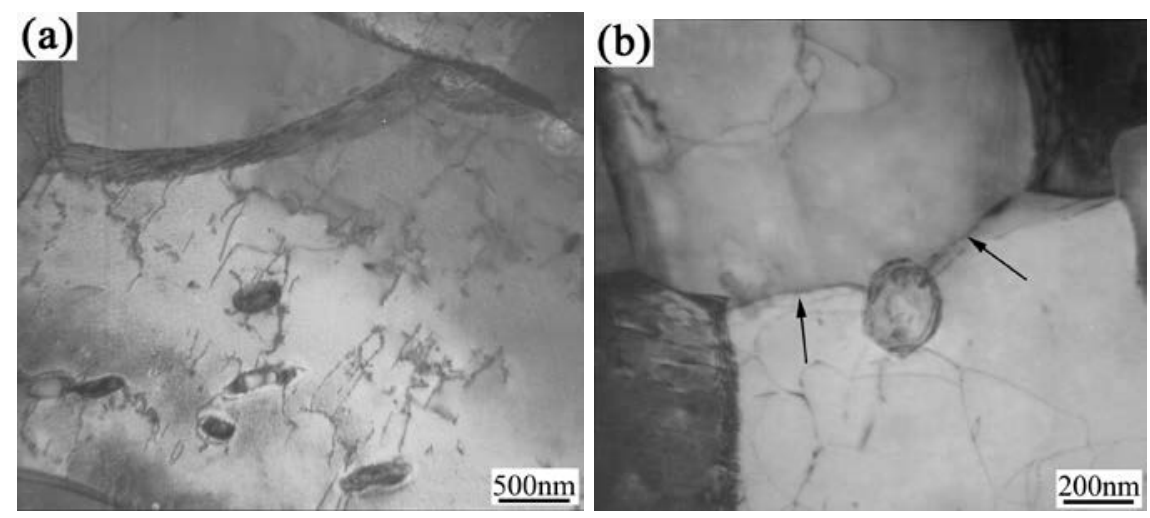

Fig.5 TEM images of Sample No.1 showing cementite particles with size smaller than $0.3 \mu \mathrm{m}$ pinning dislocations (a) and LAGB indicated by arrows (b).

\section{Conclusions}

1. DRX of ferrite occurred for both specimens during the deformation.

2. The microstructure would be refined significantly with increasing strain. On the other hand, for the specimen with small $(<0.5 \mu \mathrm{m})$ and dispersed cementites particles inside, the DRX of ferrite was slowed down comparing to the former because nucleation sites for DRX became rare, and cementites particles less than $0.3 \mu \mathrm{m}$ would hinder recovery and retard DRX by mean of pinning dislocations and inhibiting grain boundary migration.

3. PSN mechanism: In the distorted zone close to large particles, LAGBs migrate to high density dislocation areas, become HAGBs by absorbing dislocations and cause the formation of DRX nuclei.

\section{Reference}

[1] Glover G, Sellars C M. Recovery and recrystallization during high temperature deformation of $\alpha$-iron .Metall Trans, 1973; 4(5): 765 775.

[2] Li L F, Yang W Y, Sun Z Q. Dynamic recrystallization of Ferrite During Deformation At Temperature Below Ac1 In a Low Carbon Steel. Acta Metall Sin, 2003;39(4): 419-425.

[3] Murty S V S, Torizuka S, Nagai K, Kitai T, Kogo Y. Dynamic recrystallization of ferrite during warm deformation of ultrafine grained ultra-low carbon steel .Scripta Mater, 2005; 53(6):763-768.

[4] Yang W Y, Wang H M, Li L F, Sun Z Q. Dynamic Recrystallization of Ferrite in a Low Carbon Steel with Different Minor Microstructures .Acta Metall Sin, 2003; 39(7): 691-698.

[5] Humphreys F J. Recrystallization mechanisms in two-phase alloys. Metall Sci, 1979; 13(3-4): 136-145.

[6] Humphreys F J. The nucleation of recrystallization at second phase particles in deformed aluminium .Acta Metall, 1977; 25(11): 1323-1344.

[7] Humphreys F J. Particle stimulated nucleation of recrystallization at silica particles in nickel .Scripta Mater, 2000; 43 (7): 591-596.

[8] McQueen H J, Evangelista E, Bowles J, Crawford G. Hot deformation and dynamic recrystallization of Al-5Mg-0.8Mn alloy .Metal Sci, 1984;18 (8): 395-402.

[9] Nes E. The effect of a fine particle dispersion on heterogeneous recrystallization .Acta Metall, 1976; 24(5): 391-398.

[10] Gawne D T, Higgins G T. Associations between spherical particles of two dissimilar phases. J 
Mater Sci, 1971; 6(5): 403-412. 